\title{
Segurança e produção: um modelo para o planejamento e controle integrado
}

\author{
Tarcisio A. Saurin, M.Sc. \\ Doutorando do LOPP/UFRGS. \\ E-mail: saurin@vortex.ufrgs.br \\ Carlos T. Formoso, Ph.D. \\ Professor e pesquisador do NORIE/UFRGS. \\ E-mail: formoso@vortex.ufrgs.br \\ Lia B. M. Guimarães, Ph.D. \\ Professora e pesquisadora do LOPP/UFRGS. \\ E-mail: liabmg@ppgep.ufrgs.br
}

\section{Resumo}

Este artigo apresenta um modelo de planejamento e controle da segurança no trabalho (PCS) integrado ao processo de planejamento e controle da produção (PCP). 0 modelo foi desenvolvido por meio de dois estudos empíricos em obras industriais, adotando-se a pesquisa ação como estratégia de pesquisa. Os requisitos de segurança são integrados ao PCP em três níveis hierárquicos deste processo. No nível de longo prazo, o planejamento da segurança é configurado pelo desenvolvimento de análises preliminares de risco dos processos construtivos. A atualização e detalhamento da implantação destes planos é então feita por meio de sua integração aos níveis de médio e curto prazo do PCP.

\section{Palavras-chave}

Segurança no trabalho, Planejamento e controle da produção, Medição de desempenho, Construção civil.

\section{Safety and production: an integrated planning and control model}

\begin{abstract}
This paper presents a safety planning and control model [SPC] that has been integrated to the production planning and control process. The model was developed through two action research empirical studies in industrial construction projects. Safety requirements are integrated into three hierarchical levels of planning and control process. At the long-term level, safety planning is featured by preliminary hazard analysis of construction processes. These plans are updated and detailed through its integration into both medium-term and short-term planning levels.
\end{abstract}

Key words

Safety, Production planning and control, Performance measurement, Construction. 


\section{INTRODUĈ̣̃O}

Embora os custos econômicos e sociais dos acidentes de trabalho sejam altos, muitas empresas adotam como única estratégia de gestão da segurança a tentativa de estar em conformidade com as legislações vigentes. No Brasil, a principal norma de interesse do setor da construção civil é a NR-18 (Condições e Meio Ambiente de Trabalho na Indústria da Construção), cuja nova versão foi promulgada em 1995. O planejamento da segurança é um requisito chave na NR-18, a qual requer um plano de segurança e saúde denominado PCMAT (Plano de Condições e Meio Ambiente de Trabalho na Indústria da Construção), o qual tem um escopo obrigatório mínimo. Desde que a nova NR-18 foi estabelecida, a maioria das empresas tem produzido o

PCMAT com o objetivo principal de evitar multas da fiscalização governamental, não utilizando o mesmo como um instrumento prático para a gestão da segurança. As principais limitações do PCMAT são apresentadas abaixo:

a) sua implementação é normalmente considerada uma atividade extra para os gerentes, uma vez que o mesmo não é integrado às atividades rotineiras de gestão da produção. A NR-18 não requer a integração do PCMAT a outros planos, com exceção do planejamento de layout do canteiro;

b) o PCMAT é normalmente realizado por especialistas externos à empresa, havendo pouco ou nenhum envolvimento de gerentes de produção, subempreiteiros e trabalhadores;

c) o PCMAT geralmente não leva em conta a incerteza inerente aos empreendimentos de construção. Um plano às vezes excessivamente detalhado, outras vezes genérico demais, é produzido no início da etapa de produção e não é mais atualizado;

d) não há controle formal da implantação do PCMAT, o que é um dos motivos que dificultam sua atualização;

e) o PCMAT enfatiza as proteções físicas contra acidentes, normalmente negligenciando as ações gerenciais necessárias (por exemplo, implementar indicadores de desempenho pró-ativos) para a obtenção de um ambiente de trabalho seguro; e

f) o PCMAT não induz à eliminação de riscos na origem.
Em nível internacional, a Diretiva Européia 92/57/ CEE (Prescrições Mínimas de Segurança e de Saúde a Aplicar em Canteiros Móveis e Temporários), exige um plano de segurança e saúde similar ao PCMAT e, da mesma forma, não trata o planejamento como um processo gerencial. Além disso, embora a diretiva estimule o combate aos riscos na origem (principalmente através de intervenções no projeto do produto), os profissionais estão encontrando dificuldades para implementar essa abordagem (MACKENZIE et al., 2000). Este problema deve-se, em parte, à falta de ferramentas e subsídios aos projetistas e planejadores.

\section{T ais deficiências na concepção e implementação dos planos obrigatórios indicam que é necessário aperfeiçoar os métodos de planejamento e controle da segurança (PCS), indo além das exigências da legislação.}

Tais deficiências na concepção e implementação dos planos obrigatórios indicam que é necessário aperfeiçoar os métodos de planejamento e controle da segurança (PCS), indo além das exigências da legislação. Alguns estudos que têm investigado as causas dos acidentes e boas práticas para evitá-los apóiam esse argumento. Suraji e Duff (2001) por exemplo, identificaram, por meio da análise de cerca de quinhentos registros de acidentes, que deficiências no planejamento e controle foram fatores contribuintes em 45,4\% dos casos. De outra parte, duas pesquisas desenvolvidas pelo Construction Industry Institute (HINZE, 2002; LISKA et al., 1993) concluíram que, dentre várias medidas preventivas que têm sido usadas pela indústria da construção nos EUA, o planejamento da segurança antes do ínicio da obra e antes do ínicio de cada serviço é uma das mais eficientes para atingir a meta "zero acidente". Contudo, aqueles autores limitam-se a descrever sucintamente a forma de implantação do planejamento e não fazem uma análise crítica do mesmo.

Embora seja sugerida por diversos autores (HINZE, 1998; KARTAM, 1997), a integração de requisitos de segurança ao PCP tem sido relativamente pouco estudada, salientando-se pesquisas como as de Ciribini e Rigamonti (1999) e Kartam (1997). Entretanto, tais trabalhos têm se restringido a integrar a segurança a técnicas de planejamento, como o CPM (método do caminho crítico) ou a linha de balanço. Essa abordagem tende a apresentar eficiência limitada, uma vez que tem sido constatado que a ênfase do planejamento não deve ser na aplicação de técnicas e na elaboração de planos, mas sim no desenvol- 
vimento do planejamento como um processo gerencial, constituído por diversas etapas que ocorrem ciclicamente ao longo da execução da obra (LAUFER e TUCKER, 1987). Desta forma, a integração da segurança ao PCP deve ser desenvolvida sob um enfoque mais amplo, independente de técnicas específicas de planejamento.

Cabe observar que diversos requisitos do processo de PCP, como, por exemplo, a hierarquização da tomada de decisões, a continuidade, a cooperação e a visão sistêmica (LAUFER et al., 1994) parecem também ser requisitos necessários ao processo de PCS. Isso indica que ambos os processos são da mesma natureza e, em conseqüência, podem ser integrados com base em princípios comuns. Deste modo, parece haver uma oportunidade para o aperfeiçoamento dos métodos de PCS com base em conceitos e princípios que têm sido aplicados com sucesso no PCP (BALLARD, 2000; LAUFER et al., 1994; LAUFER e TUCKER, 1987). Neste contexto, o presente artigo apresenta um modelo de PCS integrado ao processo de PCP, assumindo princípios comuns na estruturação dos dois processos.

\section{MÉTODO DE PESQUISA}

A Figura 1 apresenta as etapas seguidas nesta pesquisa.

A revisão bibliográfica ocorreu ao longo de todo o período da pesquisa, estabelecendo a base teórica que fundamenta o modelo. Com esse objetivo, três áreas foram focalizadas: gestão da segurança, gerenciamento de riscos e PCP. O desenvolvimento empírico do modelo iniciou com um estudo de caso exploratório, no qual foi estabelecido um esboço de sua estrutura lógica e foram testadas algumas de suas ferramentas operacionais (SAURIN et al., 2001). A partir disso, foi conduzido o estudo empírico 1 (de janeiro a junho de 2001), o qual teve como resultado uma nova versão do modelo. Nesta etapa, sua lógica organizacional estava razoavelmente bem definida. A seguir, no estudo empírico 2 (de julho até novembro de 2001), esta lógica foi refinada e as ferramentas operacionais do modelo foram adicionalmente avaliadas em outro contexto. Cada estudo empírico foi dividido em seis etapas: a) integração da segurança ao nível de longo prazo do PCP; b) integração da segurança aos níveis de médio e curto prazo do PCP; c) implementação de um ciclo de identificação e controle de riscos baseado nas percepções dos trabalhadores; d) desenvolvimento e implementação de indicadores de desempenho em segurança; e) introdução de reuniões mensais de avaliação do desempenho em segurança; f) um seminário para discussão dos resultados do estudo.

A pesquisa ação foi a estratégia de pesquisa adotada nos estudos 1 e 2, tendo sido escolhida uma vez que a meta era desenvolver e testar um modelo de PCS em um ambiente real. De acordo com Eden e Huxham (1996), a pesquisa ação caracteriza-se por ser um processo cíclico, envolvendo o diagnóstico do problema, planejamento, ação e avaliação de resultados. Nesta abordagem, o principal foco da investigação é o resultado de uma intervenção no objeto que está sendo investigado.

Os resultados dos estudos empíricos foram avaliados segundo dois critérios, estabelecidos ainda antes do estudo inicial: utilidade do modelo e sua facilidade de uso. A

Figura 1: Delineamento da pesquisa.

\section{Revisão bibliográfica}

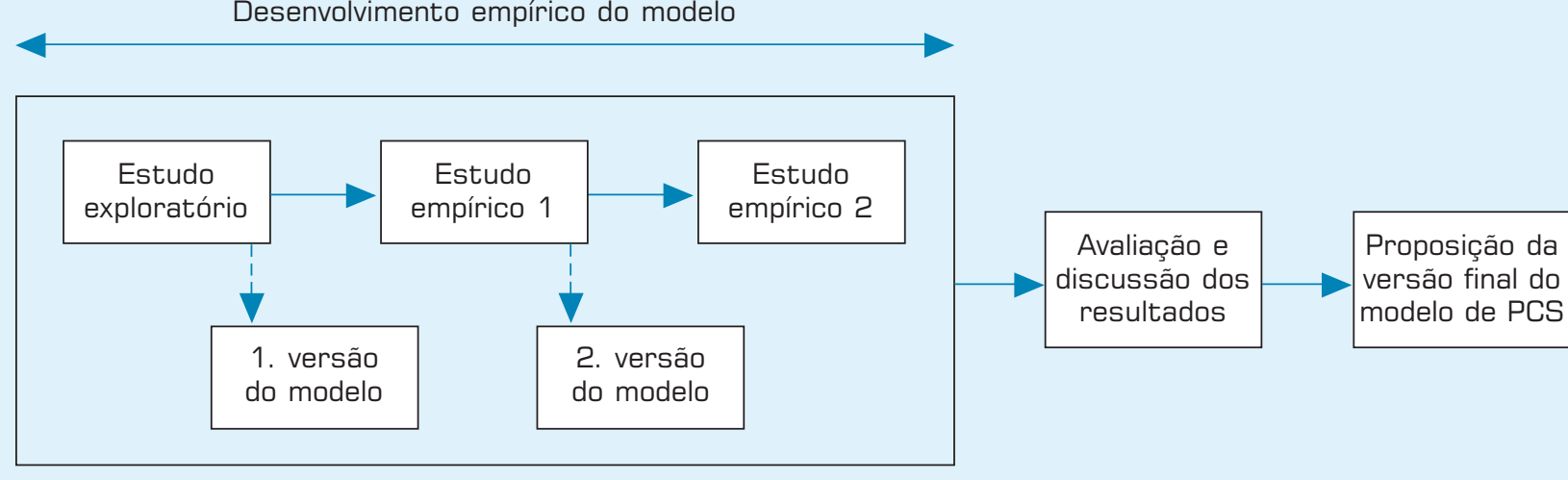


avaliação ocorreu com base em múltiplas evidências, com vistas a estabelecer um referencial consistente para as conclusões. A maior parte das evidências foi obtida a partir das diversas ações implantadas na empresa, tais como entrevistas com trabalhadores e coleta de indicadores. Contudo, outras duas fontes de evidência não são relacionadas a elementos do modelo: entrevistas realizadas com os principais intervenientes ao final de cada estudo (técnico em segurança, gerente da qualidade, representante do cliente e gerente de produção); observação participante, realizada ao longo de todo o período dos estudos empíricos. Finalmente, a partir da avaliação dos resultados, foi proposta a versão final do modelo de PCS.

\section{ESTRUTURA DO MODELO DE PCS}

A Figura 2 apresenta a estrutura do modelo de PCS desenvolvido por meio dos estudos empíricos. O planejamento e controle integrado, da segurança e da produção, ocorre em três níveis hierárquicos. O planejamento de longo prazo é desenvolvido antes do início da construção, sendo detalhado e atualizado nos níveis de médio e curto prazo. O controle da segurança envolve um conjunto de indicadores pró-ativos e reativos de desempenho, cujos resultados são discutidos em uma reunião mensal, que conta com a participação de um diretor da empresa. As opiniões dos trabalhadores são levadas em conta por meio do ciclo participatório de identificação e controle de riscos. Tal ciclo fornece informações relevantes para o PCS, indicando problemas que dificilmente seriam identificados pelos outros elementos do modelo. A difusão do planejamento da segurança aos trabalhadores é feita, basicamente, por meio de sessões de treinamento com base nos planos, antes do ínicio das respectivas atividades. Além de serem analisados nas reuniões mensais de avaliação, os indicadores são também divulgados por meio de sua discussão nas reuniões semanais de planejamento.

\section{CONTEXTO DOS ESTUDOS EMPÍRICOS}

\section{A empresa e os canteiros estudados}

Os estudos empíricos ocorreram em uma mesma empresa construtora de médio porte, escolhida devido a dois motivos: a existência de um sistema de PCP razoavelmen-

Figura 2: Estrutura do modelo de PCS.

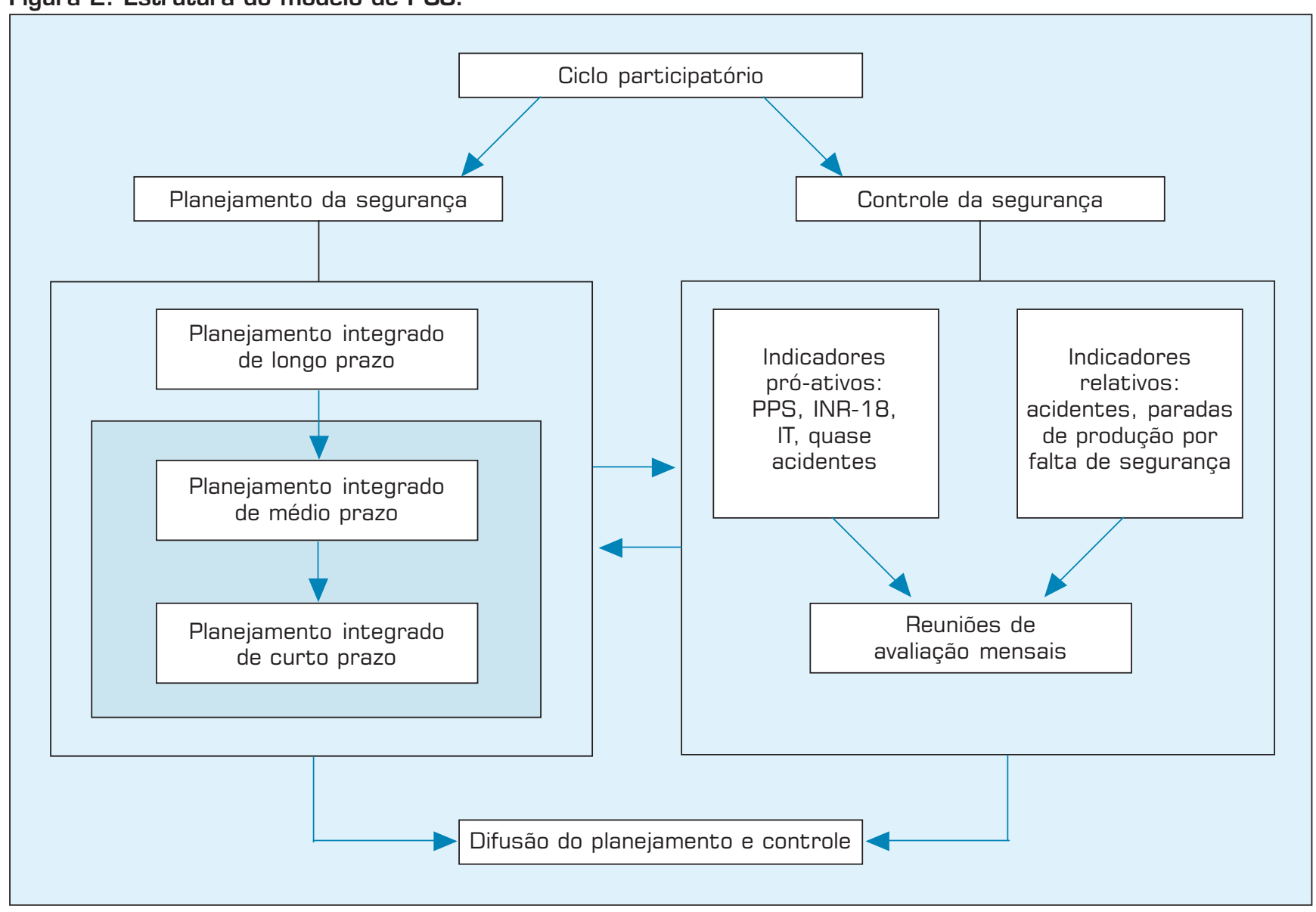


te bem estruturado; o fato de que a empresa tinha particular interesse em implantar o modelo com sucesso, uma vez que muitos de seus clientes impõem rígidas exigências de segurança aos subcontratados. Os três canteiros estudados eram localizados na região metropolitana de Porto Alegre (RS).

No estudo 1, a obra escolhida foi a reforma do prédio de uma aciaria, setor de uma siderúrgica dedicado ao derretimento de sucata em altos fornos. Neste artigo, este empreendimento é denominado de obra A. Embora a construção tenha durado aproximadamente seis meses, o estudo ocorreu ao longo dos seus quatro meses iniciais. Similarmente ao que ocorre em muitas obras de manutenção industrial, a produção da aciaria não foi interrompida em função dos trabalhos de construção. Assim, os riscos ambientais da aciaria também afetaram os trabalhadores da obra, tornando a mesma um empreendimento de alto risco em termos de segurança no trabalho. O estudo 2 foi conduzido na construção de dois laboratórios em uma planta petroquímica, denominados obras B1 e B2. A obra B1 consistia de uma

trabalho para cada equipe. O indicador PPC - Percentual de Planos Concluídos (BALLARD, 2000) - era calculado com periodicidade diária e semanal. No que diz respeito ao planejamento de médio prazo, sua principal função era apoiar a remoção das restrições relacionadas aos pacotes de trabalho. Assim, um plano com horizonte de três semanas era produzido semanalmente, contendo uma lista de restrições (por exemplo, espaço, materiais, mão-de-obra e equipamentos) e a data limite para sua remoção. Finalmente, o plano de longo prazo, que levava em conta todo o período de construção, era atualizado mensalmente.

\section{DESENVOLVIMENTO DOS ESTUDOS EMPÍRICOS}

\section{Integração da segurança ao nível de longo prazo do PCP}

O planejamento da segurança no nível de longo prazo considera as grandes etapas de construção estabelecidas nos planos de longo prazo de produção. Para cada etapa (por exemplo, troca do telhado ou troca de janelas) um plano de segurança foi desenvolvido usando a técnica da

edificação de um pavimento (área de $190 \mathrm{~m}^{2}$ ) e foi finalizada em três meses. A obra B2 era um prédio de três pavimentos, com $2.430 \mathrm{~m}^{2}$ de área. Similarmente ao que aconteceu na obra $\mathrm{A}$, o estudo empírico ocorreu ao longo dos quatro primeiros meses da obra B2, cujo prazo contratual era de seis meses. Novamente, o elevado risco de acidentes foi o motivo da escolha destas obras, especialmente a B2, cuja execução envolvia uso de estruturas metálicas e pré-moldadas de grande porte. Os três canteiros estudados contavam com um técnico de segurança, da construtora, em tempo integral.

\section{Procedimentos existentes de planejamento e controle da produção}

Em ambos os estudos empíricos, o processo de PCP existente tinha a mesma configuração e era baseado no método Last Planner de controle da produção (BALLARD, 2000). Existiam três níveis de planejamento e controle, diferenciados segundo o horizonte de planejamento: curto, médio e longo prazo. No nível de curto prazo, os pacotes de trabalho eram alocados preliminarmente para as diferentes equipes em reuniões semanais. Contudo, devido à variabilidade do ambiente de trabalho, os planos semanais necessitavam ser reavaliados em reuniões diárias, nas quais era feita a definição final das áreas de
Análise Preliminar de Riscos (APR). Tal técnica é largamente utilizada para o planejamento da segurança (KOLLURU et al., 1996) uma vez que ela abrange as principais etapas do ciclo de gerenciamento de riscos. De acordo com a lógica do modelo, os planos de segurança são categorizados em dois grupos:

a) o primeiro envolve atividades cujos riscos nem sempre podem ser claramente associados a pacotes de trabalho específicos. Como exemplo, no estudo empírico 2, seis planos foram enquadrados nesta categoria: áreas de vivência, riscos das áreas de circulação comuns, equipamentos fixos de transporte vertical, central de armação, central de fôrmas, central de produção de concreto e argamassa. Ilustrando o princípio adotado, os riscos das áreas de circulação comuns não podem ser alocados a um pacote em particular, pois na verdade esses riscos interagem com todos os pacotes;

b) o segundo envolve atividades cujos riscos sempre podem ser claramente associados a pacotes de trabalho específicos. Nos dois estudos, a maioria dos planos foi incluída nesta categoria, tais como: pinturas, coberturas, montagem e trabalho sobre andaimes fachadeiros. Além disso, este grupo inclui planos específicos para atividades que se repetem em várias etapas da obra. Como exemplo, os 
serviços de soldagem ocorriam nas etapas de estrutura metálica, de instalações hidráulicas e de impermeabilizações. Assim, foi mais simples elaborar um plano específico para soldagem e, quando pertinente, apenas referenciar tal plano no texto dos restantes.

A versão inicial de todos os planos foi elaborada por um membro da equipe de pesquisadores, sendo que, a partir disso, ocorreram reuniões individuais com o técnico em segurança, o gerente de produção e representantes de subempreiteiros e do cliente. Além disso, os planos também foram discutidos em reuniões da CIPA (Comissão Interna de Prevenção de Acidentes), propiciando a obtenção das contribuições de mestres-de-obras. Os procedimentos adotados para elaborar os planos de segurança foram os seguintes:

a) estabelecer os passos necessários para executar a atividade: considerar as atividades de conversão (por exemplo, colocar tijolos na parede) e as atividades de fluxo (por exemplo, transportar ou armazenar materiais);

b) identificar os riscos: tal etapa inclui identificar riscos de qualquer natureza em cada passo do processo, ou seja, choques elétricos, quedas de materiais, etc. $\mathrm{O}$ esforço para identificar riscos envolveu, basicamente, visitas aos canteiros, consulta à literatura, análise dos projetos e as já citadas reuniões de discussão dos planos. A fim de estabelecer uma linguagem comum para todos os planos, também foi adotada uma classificação de riscos nesta etapa (por exemplo, soterramentos, quedas de materiais, etc.);

c) definir como cada risco será controlado: considerando que o controle é baseado no que está escrito nos planos, é importante não prescrever controles quando não há recursos para implementá-los ou quando não se acredita que eles são realmente necessários. Embora a meta seja eliminar todos os riscos, tal objetivo é raramente possível e riscos residuais são retidos pela empresa. Assim, a solução é manter os riscos residuais dentro de um nível tolerável, cabendo aos planejadores definir o que é tolerável ou não. Nesta pesquisa, não foi feita uma avaliação de riscos formal - calcular severidade versus probabilidade para cada perigo e decidir se o risco resultante é aceitável ou não - para estabelecerse a magnitude das medidas de segurança. Tendo em vista a subjetividade das avaliações de risco (TAH, 1997), assim como as restrições de prazo para conclusão da pesquisa, considerou-se que o custo-benefício desta atividade não justificaria sua realização para cada plano de segurança.

Os planos de longo prazo são a referência para a integração da segurança aos níveis de médio e curto prazo do PCP. Devido à menor incerteza, dois objetivos são viáveis de serem cumpridos nestes níveis:

a) atualizar os planos de longo prazo, uma vez que, ao longo da excução da obra, novos riscos podem ser identificados, assim como riscos já previstos podem ser melhor compreendidos;

\section{usado para avaliar o desempenho similar ao PPC, sendo denominado PPS (Percentual de Pacotes de Trabalho Seguros).}

b) detalhar a implementação dos planos de longo prazo. Mesmo para riscos usuais e amplamente conhecidos, muitas vezes é necessário detalhar como as medidas de controle serão implementadas.

\section{Integração da segurança ao nível de médio prazo do PCP}

As reuniões de planejamento no nível de médio prazo ocorriam semanalmente, envolvendo os seguintes intervenientes: gerente de produção, gerente de qualidade, técnico em segurança, representantes de subempreiteiros e um membro da equipe de pesquisa. O nível de médio prazo cumpre a importante função de programação de recursos relacionados à seguranca, atividade que faz parte da análise de restrições realizada para cada pacote de trabalho. De acordo com a proposta do modelo, as restrições de segurança incluem tanto a aquisição de recursos, quanto a implantação das medidas preventivas.

Ao longo da pesquisa, verificou-se que as restrições (e os respectivos recursos) relacionadas à segurança podem ser de cinco tipos: proteções coletivas, treinamento, projeto de instalações de segurança, equipamentos de proteção individual (EPI) e espaço. A tabela 1 apresenta exemplos de recursos para cada uma das categorias. Cada um destes recursos pode estar associado a uma ou mais restrições. Como exemplo, restrições relacionadas à sinalização de segurança, tanto podem ser a fabricação das placas, quanto a sua implantação ou realocação no canteiro.

No nível de médio prazo ainda começa a ser detalhado o método de execução de cada pacote. Tal atividade deve levar em conta as necessidades de segurança e assume maior relevância, para aquela finalidade, quando os métodos são discutidos ao nível das operações desempenhadas 
pelos trabalhadores. Ao longo das reuniões, percebeu-se que esse último aspecto era normalmente negligenciado pelos planejadores, os quais assumiam que as equipes saberiam como executar suas atividades. Assim, com vistas a induzir a discussão dos métodos sob a ótica da segurança, sistematicamente foram introduzidas questões como as seguintes: onde serão fixados os cintos de seguranca? Como os trabalhadores acessarão o posto de trabalho? Uma vez que a incerteza ainda é relativamente alta neste nível, tornava-se difícil chegar a uma proposta definitiva a respeito dos métodos. Normalmente, duas ou três alternativas potencialmente seguras eram levantadas e a decisão final era tomada no nível de curto prazo. $\mathrm{O}$ teste prático das alternativas também contribuía para a decisão final.

\section{Integração da segurança ao nível de curto prazo do PCP}

Neste nível, as medidas de segurança eram discutidas em reuniões com periodicidade diária e semanal. As últimas eram as mais importantes em termos de tomada de decisão, uma vez que, além dos mesmos intervenientes já presentes nas reuniões de médio prazo, também estavam presentes representantes do cliente. Além disso, os indicadores de desempenho de PCS e PCP eram apresentados e discutidos nestas reuniões. Em relação às reuniões diárias, as mesmas tinham como objetivo reavaliar o planejamento semanal e, a partir disso, obter permissões de trabalho fornecidas pelo cliente. Seguindo a lógica do método Last Planner, as reuniões no nível de curto prazo tinham caráter de comprometimento, o que, nesse caso, incluía tanto as metas de produção quanto as metas de segurança.

No nível de curto prazo, o planejamento da segurança pode requerer a tomada de decisões com periodicidade diária, mesmo que não existam reuniões formais. Isso é necessário, uma vez que um pacote de trabalho que se desenvolve ao longo de vários dias, possivelmente vai envolver atividades em diferentes alturas e locais. Em consequiência, proteções como guarda-corpos e cabos guia para fixar cintos, exemplos identificados nos estudos 1 e 2 , devem ser continuamente ajustadas conforme a movimentação física das equipes. O planejamento de curto prazo também oportunizou a extensão do conceito de produção protegida, uma das principais técnicas do método Last Planner. Tal conceito sugere que um pacote de trabalho somente deve ser alocado para execução se ele atende a cinco requisitos: definição, seqüenciamento, quantidade, aprendizagem e disponibilidade (BALLARD, 2000). Nesta pesquisa, a segurança foi considerada como parte do requisito disponibilidade.

\section{Controle da segurança}

\section{Percentual de Pacotes de Trabalho Seguros (PPS)}

O principal indicador usado para avaliar o desempenho em segurança é similar ao PPC, sendo denominado PPS (Percentual de Pacotes de Trabalho Seguros). O PPS indica a percentagem de pacotes de trabalho que foram executados de modo seguro. Um pacote é considerado seguro quando todas as medidas preventivas planejadas foram implementadas $\underline{\mathbf{e}}$ quando não ocorreu nenhum acidente, quase-acidente ou outro evento imprevisto. A fórmula usada para calcular o PPS é apresentada abaixo:

$$
\text { PPS }=\frac{\sum \text { pacotes de trabalho seguros }}{\sum \text { total de pacotes de trabalho }}
$$

A Figura 3 ilustra o formulário usado para a coleta do PPS nos estudos empíricos. O formulário é dividido em duas seções, de acordo com a já apresentada classificação dos planos de longo prazo. Novamente de modo similar ao método Last Planner, as causas para o não cumprimento dos planos são identificadas. Um check-list de problemas usuais é usado como referência para esta análise.

Embora seja similar ao PPC, a coleta de dados para o PPS é mais difícil, uma vez que alguns problemas somente podem ser identificados por meio da observação de todas as atividades durante todo o tempo. Assim, um modo viável de coleta é através de observações diretas amostrais

Tabela 1: Exemplos de recursos relacionados à segurança.

\begin{tabular}{|l|l|}
\hline \multicolumn{1}{|c|}{ Categoria } & \multicolumn{1}{c|}{ Exemplos de recursos } \\
\hline Treinamento & treinamento de integração de novos funcionários, treinamento nos planos de segurança, vídeos de treinamento. \\
\hline Proteções coletivas & guarda-corpos, sinalização de segurança, plataformas de proteção, extintores de incêndio, telas de segurança. \\
\hline EPI & capacetes, luvas, botinas, máscaras, óculos de segurança, protetores auriculares, cintos de segurança. \\
\hline Projeto & detalhamentos da execução de andaimes, anotações de responsabilidade técnica dos projetos destas instalações. \\
\hline Espaço & áreas para estoque de materiais, negociação de áreas de trabalho livres de interferência das operações do cliente. \\
\hline
\end{tabular}


de todas as atividades. A tabulação em nível diário é preferível, uma vez que a tabulação em nível semanal, para maior confiabilidade, exige dados de todos os dias da semana. Uma vez que os procedimentos de coleta ainda não estavam suficientemente maduros na época do estudo 1, naquele caso a coleta foi feita apenas por membros da equipe de pesquisa. De outra parte, no estudo 2 o técnico em segurança contribuiu com 21,5\% dos dados coletados. Enquanto o técnico não alocava um período de tempo específico para a coleta, os pesquisadores costumavam gastar entre uma e duas horas por dia nesta atividade.

\section{Outras medidas de controle}

Além do PPS, outros dados de desempenho foram coletados. Dois deles eram de natureza reativa: o número de acidentes e o número de paradas de produção decorrentes de falta de segurança. Em relação aos dados próativos, três foram coletados: (a) índice de adequação à NR-18 (INR-18), avaliado por meio de um check-list da norma; (b) índice de treinamento (IT), calculado por meio da relação entre o número de homens-hora treinados e o número total de homens-hora trabalhadas; (c) documentação e investigação dos quase-acidentes, os quais foram relatados pelos técnicos em segurança e pelos responsáveis pela coleta do PPS. Os resultados de todos os indicadores eram compilados em um relatório, cujo conteúdo era discutido em uma reunião de avaliação mensal. Ao longo dos dois estudos, ocorreram sete destas reuniões, envolvendo, no mínimo, um membro da direção da empresa, o gerente de produção, o técnico em segurança, o gerente de qualidade e um membro da equipe de pesquisa, responsável por produzir o relatório e coordenar a reunião.

\section{Participação dos trabalhadores}

Os trabalhadores devem ser envolvidos no processo de PCS, uma vez que eles são os usuários finais e principais beneficiários dos planos. Tendo isso em vista, o modelo propõe um ciclo de identificação e controle de riscos baseado nas percepções dos trabalhadores, ilustrado na Figura 4.
A primeira etapa envolve entrevistas com grupos de trabalhadores, tipicamente oito. As entrevistas são divididas em duas etapas: a) uma seção aberta, na qual os trabalhadores são encorajados a falar sobre aspectos positivos e negativos do trabalho como um todo, e não apenas sobre suas tarefas; b) uma seção induzida na qual os trabalhadores são solicitados a falar sobre assuntos específicos. Nessa seção é usado um check-list de questões que inclui tópicos como manuseio manual de cargas, posturas incômodas ou EPI. Quando um problema é relatado, os trabalhadores são solicitados a apresentarem sugestões para sua resolução. A segunda etapa é discutir os resultados das entrevistas em uma reunião de nível gerencial, incluindo a participação de um membro da alta direção. Em tal reunião é estabelecido o primeiro esboço de um plano de ação para resolver os problemas relatados. A terceira etapa é uma reunião de feedback envolvendo trabalhadores e gerentes. O plano de ação é apresentado e discutido com os trabalhadores, sendo esclarecidos os motivos que levaram a gerência a não atender alguma demanda. Além disso, a reunião é uma oportunidade para o relato de novos problemas, para a apresentação de novas sugestões e, também, para a eliminação de falhas na comunicação entre o nível gerencial e o operacional. Finalmente, a quarta etapa consiste em avaliar a satisfação dos trabalhadores com a implementação (ou falta de) das melhorias. A avaliação ocorre no âmbito de uma nova rodada de entrevistas, na qual também é buscada a identificação de novos riscos e a reavaliação dos controles existentes. O modelo não propõe um intervalo rígido para a condução de uma nova rodada de entrevistas. Contudo, recomenda-se fazer novas entrevistas quando novas equipes se integram à obra.

Dois ciclos ocorreram em cada estudo empírico. Em ambos os casos, a primeira rodada de entrevistas foi conduzida aproximadamente três semanas após o início da obra, quando os trabalhadores estavam razoavelmente familiarizados com o ambiente de trabalho. A segunda rodada ocorreu aproximadamente quarenta dias após a primeira, quando novas equipes já tinham ingressado no canteiro. As entrevistas envolveram grupos de oito trabalhadores, em média, e todas as discussões foram gravadas.

Figura 3: Exemplo de formulário usado para a coleta do indicador PPS.

\begin{tabular}{|c|c|c|c|c|c|}
\hline \multirow[b]{2}{*}{ Equipe } & \multirow[b]{2}{*}{ Pacotes de trabalho } & \multirow[b]{2}{*}{ № APR } & \multicolumn{2}{|c|}{ Seguro? } & \multirow[b]{2}{*}{ Problema } \\
\hline & & & Sim & Não & \\
\hline \multirow[t]{2}{*}{ Pintura } & Parede externa, escritório & APR 5 & & $x$ & Falta de uso de óculos \\
\hline & Planos não associados a pacotes & & & & \\
\hline BSF & Áreas de circulação comuns & APR 8 & $x$ & & \\
\hline
\end{tabular}




\section{PRINCIPAIS RESULTADOS} DOS ESTUDOS EMPÍRICOS

\section{Indicadores de desempenho}

Considerando ambos os estudos, foram registrados dois acidentes com afastamento e vinte e um quase-acidentes. Além disso, no estudo 1 ocorreram três paradas parciais de produção causadas por falta de segurança. Uma destas situações ilustra a importância da análise de restrições: a equipe de manutenção do guindaste não pôde entrar na siderúrgica para consertar aquele equipamento, uma vez que eles não tinham assistido à palestra de integração, ministrada somente nas segundas-feiras. Assim, até que a equipe assistisse à palestra, o guindaste ficou paralisado por três dias, inviabilizando a execução de diversas tarefas na obra. O indicador PPS foi coletado nos três canteiros estudados. Como ilustração dos resultados, a Figura 5 apresenta a evolução do PPS e do PPC na obra B1, onde foi possível coletar dados desde o ínicio até o final da construção.

No exemplo da Figura 5, existem oito dias em que o PPS e o PPC possuem valores acima de $80 \%$. Isso indica a viabilidade de atingir bom desempenho simultaneamente nos processos de PCS e PCP. De fato, um estudo conduzido por Hinze e Parker (1978) indicou que segurança e produtividade não estão em conflito, parecendo ter uma correlação positiva. Contudo, não foi encontrada correlação estatística entre PPS e PPC neste estudo ( $p$-value $=0,7$ na obra A; 0,5 na obra B1 e 0,8 na obra B2). As causas para o não cumprimento dos planos, avaliadas por ocasião da coleta do PPS, indicavam as prioridades para a tomada de ações corretivas. No caso da obra A, por exemplo, as falhas no planejamento das proteções coletivas foram o principal problema.

\section{Percepções dos trabalhadores}

Como ilustração das percepções dos trabalhadores, a Tabela 2 apresenta parte dos resultados da primeira rodada de entrevistas no estudo 1 . Todas as demandas foram classificadas de acordo com sua natureza, em cinco categorias: meio ambiente (MA), incluindo assuntos como níveis de ruído e iluminação; projeto de processos e postos de trabalho (PPP); recursos humanos $(\mathrm{RH})$; EPI e treinamento (TRE).

Várias demandas indicaram que alguns controles de risco existentes não estavam sendo eficientes. Como exem-

Figura 4: Ciclo de identificação e controle de riscos baseado nas percepções dos trabalhadores.

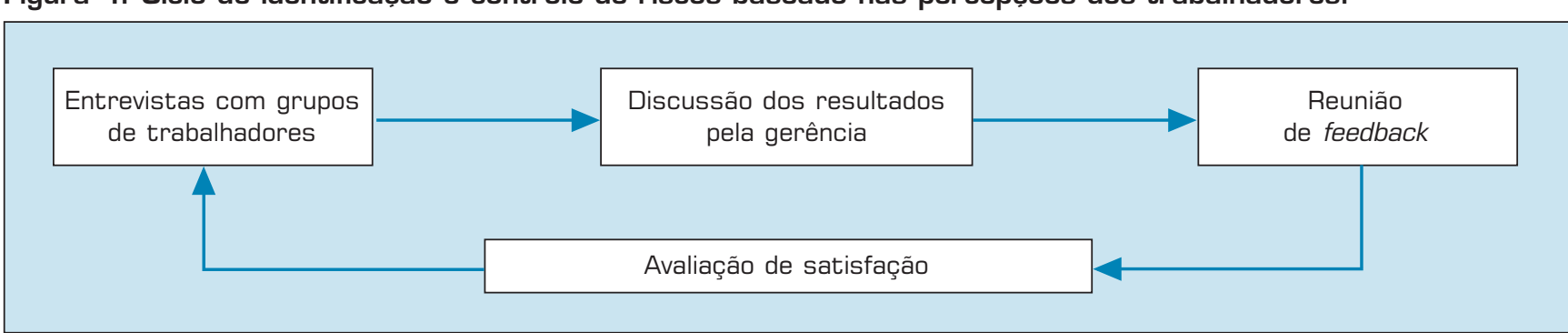

Figura 5: Evolução do PPS e do PPC [obra B1).

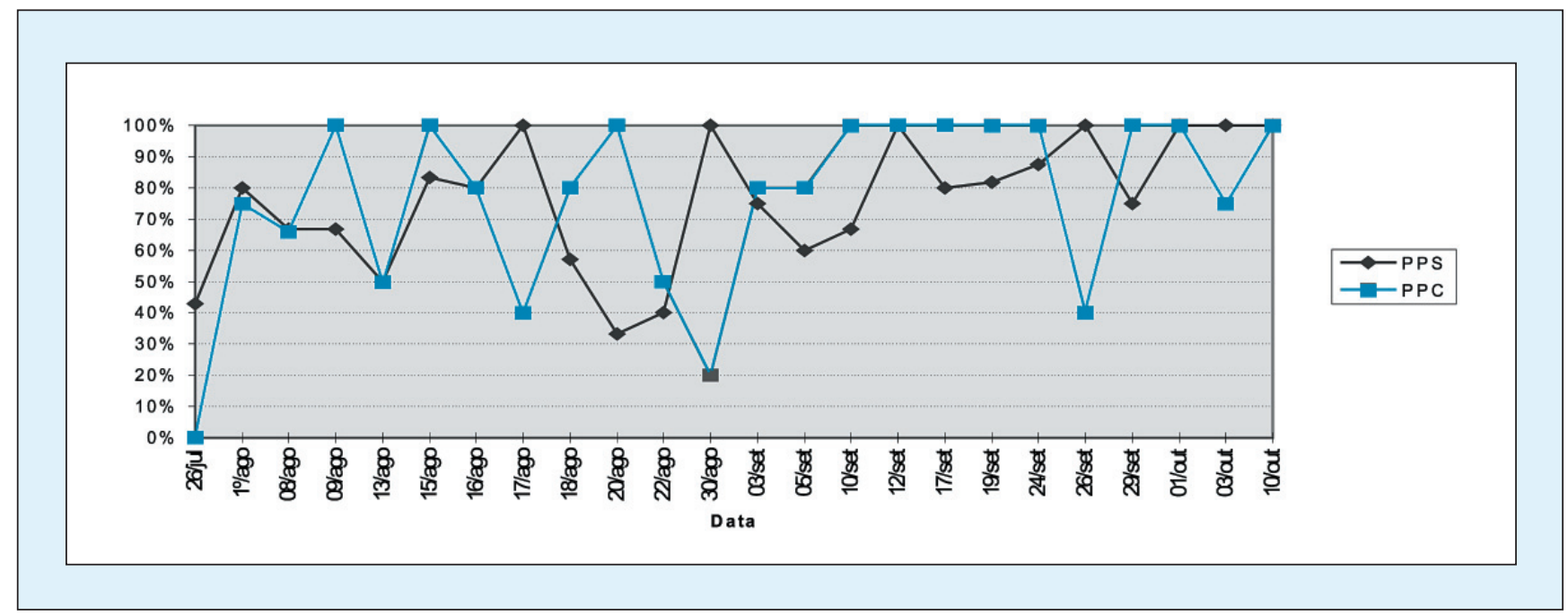


plo, os problemas 3 e 4 sugeriam que outros modelos de cintos de segurança deveriam ser adquiridos. Outros problemas indicaram riscos que não haviam sido identificados no planejamento. Como exemplo, a equipe de recuperação estrutural reclamou que estava montando seus próprios andaimes (problema 5), embora eles não tivessem experiência prévia nesta atividade. Seguindo a análise das demandas, a gerência da obra produziu um plano de ação para sua resolução. Tal plano foi apresentado e discutido em uma reunião de feedback envolvendo trabalhadores e gerentes. $\mathrm{O}$ primeiro ciclo participatório encerrou com uma segunda rodada de entrevistas, na qual os trabalhadores avaliaram a implantação do plano de ação. Com base nesta avaliação, uma nova tabela foi produzida, indicando se as demandas foram totalmente resolvidas, parcialmente resolvidas ou não resolvidas.

\section{AVALIAĈ̣̃O DO MODELO}

\section{Utilidade}

\section{Contribuição para a}

\section{identificação e controle de riscos}

As reuniões de planejamento integrado contribuíram tanto para a sistemática identificação de riscos quanto para o melhor entendimento dos riscos já conhecidos. Notadamente, esta contribuição manifestava-se quando da discussão do método executivo e logística dos pacotes de trabalho, momentos em que os planos eram detalhados. Os riscos identificados nestas reuniões eram, na grande maioria, relacionados à possibilidade de acidentes causados pela ausência ou implantação inadequada das instalações de segurança. Além de sua função primária de controle, a coleta dos indicadores também revelou ser outra oportunidade para a identificação de riscos, uma vez que o responsável pela coleta circulava pelo canteiro e observava criticamente os diversos postos de trabalho. Em geral, os riscos e controles ineficientes identificados com apoio dos indicadores tinham a mesma natureza daqueles percebidos nas reuniões de planejamento. Como resultado das reuniões de planejamento e da coleta dos indicadores, quarenta e dois novos riscos foram identificados ao longo dos estudos 1 e 2 .

\section{s trabalhadores devem ser envolvidos no processo de PCS, uma vez que eles são os usuários finais dos planos.}

De outro lado, o ciclo participatório indicou problemas que dificilmente seriam identificados ou percebidos como relevantes por meio das reuniões de planejamento e da coleta dos indicadores. A natureza das demandas dos trabalhadores explica essa particularidade, uma vez que muitas delas envolviam assuntos de recursos humanos e treinamento. Contudo, mesmo demandas teoricamente identificáveis por meio de simples inspeção visual, como as relacionadas à EPI, MA e PPP, freqüentemente requerem consulta aos trabalhadores para serem de fato compreendidas. No âmbito das cinqüienta e nove demandas levantadas nos dois estudos, $27,1 \%$ corresponderam a riscos que não tinham sido identificados, enquanto que $62,9 \%$ corresponderam a controles ineficientes.

\section{Contribuição para o atendimento de exigências externas}

Em ambos os estudos, o cliente conduziu uma auditoria na gestão de segurança das obras. As auditorias deram uma avaliação positiva dos canteiros, considerando o modelo de PCS como um benchmark dentre as práticas adotadas pelos seus subcontratados. A satisfação dos clientes também foi percebida nas entrevistas de avaliação com seus representantes. Como exemplo, em um dos relatos foi comentado que era reconhecida a existência de um sistema permanente

Tabela 2: Exemplos de problemas de acordo com as percepções dos trabalhadores (estudo 1).

\begin{tabular}{|c|c|}
\hline Problemas & Tipo \\
\hline 1. Poeira excessiva. & MA \\
\hline 2. Vestiários são desorganizados e sujos. & $\mathrm{RH}$ \\
\hline 3. Cintos de segurança não se ajustam a diferentes tamanhos de pessoas. & EPI \\
\hline 4. Cintos de segurança com dois cabos são necessários para trabalhos sobre andaimes. & EPI \\
\hline 5. Equipe de recuperação estrutural estava montando andaimes sem experiência prévia. & TRE \\
\hline 6. Falta de conhecimento sobre as áreas de risco da aciaria (onde o acesso é proibido ?]. & TRE \\
\hline
\end{tabular}


de gestão da segurança e, em conseqüência, os esforços de segurança não dependiam mais de campanhas ocasionais. $\mathrm{O}$ nível de conformidade com a NR-18 foi avaliado nos dois estudos: $90 \%$ dos requisitos aplicáveis eram cumpridos na obra A, enquanto que $77 \%$ eram cumpridos nas obras B1 e B2. Além disso, o modelo inclui práticas mais avançadas do que aquelas requisitadas pelo PCMAT, como indicadores pró-ativos e procedimentos para atualizar os planos de segurança.

\section{Facilidade de uso}

\section{Eficiência do processo de PCS}

De acordo com as entrevistas, a inclusão de requisitos de segurança a procedimentos já existentes na empresa tendeu a facilitar a implantação do modelo. Nas seguintes situações o modelo foi integrado às rotinas existentes, evitando a demanda de tempo adicional dos gerentes: nas reuniões de planejamento, que passaram a incluir PCP e PCS; nas reuniões semanais do sistema da qualidade, no âmbito das quais ocorreram três reuniões mensais de avaliação do PCS das obras estudadas; nas sessões de treinamento, que a partir do estudo 2 incluíram procedimen-

\section{Integração da segurança ao PCP}

Inicialmente, cabe enfatizar que ficou evidente a necessidade de atualização dos planos de longo prazo, uma vez que vários novos riscos foram identificados após o início da etapa de produção. Apesar disso, deve-se considerar que muitas das medidas de segurança apresentadas nos planos de longo prazo são válidas para qualquer canteiro. Assim, parece viável que tais planos sejam padronizados e apenas adaptados em função das particularidades de cada obra. Como uma oportunidade de melhoria neste nível, dois entrevistados sugeriram a inclusão de ilustrações nos planos, a fim de esclarecer as medidas de segurança.

A análise de restrições, no nível de médio prazo, estabeleceu um vínculo entre os planos de longo e os de curto prazo. Assim, diversas restrições eram relacionadas à disponibilização de recursos indicados nos planos de longo prazo, tais como andaimes e guarda-corpos, por exemplo. Dois outros fatores também indicam os vínculos entre o longo prazo e os demais níveis: nas reuniões de médio e curto prazo não era necessário despender tempo discutindo medidas preventivas básicas, já estabelecidas no longo prazo; ao longo das intervenções foi verificado que todos os pacotes de trabalho podiam ser associados a um ou mais planos de longo prazo, de modo que isso demonstra que o nível de agregação adotado para estes planos foi adequado. Além disso, a coleta do PPS tem os planos de longo prazo como referencial, existindo um forte vínculo entre estes dois elementos do modelo. Em relação aos vínculos entre o médio e o curto prazo, as duas intervenções indicaram que o método executivo deve ser discutido em ambos. Contudo, as discussões no médio prazo têm caráter mais genérico e abordam várias alternativas, proporcionando subsídios para a decisão final no nível de curto prazo. tos de segurança e execução de forma integrada; nas reuniões da CIPA, utilizadas duas vezes para discussão dos planos de longo prazo. Similarmente, a implantação do modelo foi integrada às atividades do técnico em segurança, levando ao enriquecimento e ao alargamento de suas atividades.

A eficiência do processo pode ainda ser avaliada em função da demanda de recursos para implementar o modelo. Como exemplo, as duas intervenções indicaram que a coleta e análise dos indicadores demanda dois requisitos básicos: o responsável pela coleta, seja externo ou interno à obra, deve ter tempo disponível para circular pelo canteiro e observar todos os postos de trabalho (de uma a duas horas por dia); o responsável deve ter tempo disponível para analisar os dados e produzir gráficos e tabelas com os resultados, tipicamente, cinco horas por mês nesta pesquisa. A implementação do ciclo participatório também tem seus pré-requisitos: o responsável pela condução das entrevistas preferencialmente não deve ter relação de chefia com os trabalhadores; o entrevistador deve conhecer as regras básicas do processo de entrevistas, tais como não induzir os entrevistados e usar um roteiro de perguntas; o responsável deve ter tempo disponível para analisar as entrevistas e produzir tabelas com os resultados, tipicamente, quatro horas por rodada de entrevista nesta pesquisa; o canteiro deve possuir um local onde os trabalhadores possam ser entrevistados com privacidade e o mínimo de conforto.

\section{Compreensão do modelo pelos intervenientes}

Em ambos os estudos, os entrevistados salientaram que a experiência contribuiu para o amadurecimento do senso crítico em relação à prevenção de acidentes, indicando que foram sensibilizados pela busca da visão sistêmica do processo, em detrimento da busca de culpados pelas falhas. De 
certo modo, pode-se dizer que os participantes pareceram ter assimilado que, além do combate aos erros humanos, há uma série de procedimentos de planejamento e controle que tem importância decisiva para a prevenção dos acidentes. Outras evidências também indicaram que o modelo foi satisfatoriamente compreendido. Sem envolvimento da equipe de pesquisa, o modelo foi implementado em um terceiro empreendimento, sob a coordenação do gerente da qualidade e com o apoio dos técnicos de segurança envolvidos nos estudos 1 e 2 . Além disso, nas entrevistas de avaliação, nenhum entrevistado apontou dificuldades para compreender o modelo, embora tenham enfatizado a necessidade de um treinamento básico para esclarecer sua lógica.

\section{CONCLUSÕES}

Este artigo apresentou um modelo de planejamento e controle da segurança (PCS) o qual foi desenvolvido por meio de dois estudos empíricos em obras industriais. Os resultados indicaram que vários conceitos e métodos que têm sido usados com sucesso no PCP (tais como análise de restrições, análise de causas para o não cumprimento de planos e produção protegida) podem ser estendidos para a gestão da segurança. Em nível mais genérico, os requisitos- chave do processo de PCP foram incorporados ao modelo de PCS: hierarquização da tomada de decisões, continuidade, visão sistêmica e participação dos diferentes intervenientes. Assim, foi estabelecido um processo hierárquico de tomada de decisão a respeito das medidas de segurança: a técnica da Análise Preliminar de Riscos (APR) foi usada para produzir planos de longo prazo, os quais foram continuamente detalhados e atualizados por meio da sua integração aos níveis de médio e curto prazo do PCP. Devido à integração nesses níveis, o PCS ocorre de modo sistemático e contínuo ao longo de toda a etapa de produção. Considerase que a visão sistêmica do PCS foi obtida, uma vez que as ferramentas de identificação e controle de riscos dão visibilidade a uma ampla gama de riscos de diversas naturezas. $\mathrm{O}$ modelo de PCS também tem caráter participativo, uma vez que há mecanismos para envolvimento dos principais intervenientes.

Embora seja amplamente aceito que a segurança deve ser integrada em praticamente todos os processos gerenciais, é necessário ampliar os esforços de pesquisa nesse sentido. A integração da segurança à etapa de desenvolvimento do produto seria uma continuidade natural desta pesquisa, podendo-se desenvolver um modelo de PCS que inclua as etapas de projeto e produção.

\section{- Referências bibliográficas}

BALLARD, G. The Last Planner System of Production Control, 2000. 120 p. PhD thesis. School of Civil Engineering, University of Birmingham, UK.

BAKER, S., PONNIAH, D., SMITH, S. Risk response techniques employed currently for major projects. Construction Management and Economics. Reading, UK, v. 17, n.2, p. 205-213. Mar, 1999.

CIRIBINI, A., RIGAMONTI, G. Time/ space chart drawings techniques for the safety management. In: International Conference of Cib Working Commission W99, 2., 1999, Hawaii. Proceedings... Rotterdam: A. A. Balkema, 1999. p. 25-32.

EDEN, C., HUXHAM, C. Action research for management research. British Journa of Management, London, v. 7, n.2, p. 7586. 1996.
HINZE, J. Making zero injuries a reality. Gainesville: University of Florida, 2002. 110 p. A report to the Construction Industry Institute (Report 160).

HINZE, J. Construction Planning and Scheduling. Upper Saddle River: PrenticeHall, 1998, 326 p.

HINZE, J.; PARKER, H. Safety: productivity and job pressures. Journal of the Construction Division, v.104, n. 1, p. 27-34. 1978.

KARTAM, N. Integrating safety and health performance into construction CPM. Journal of Construction Engineering and Management, New York, NY, v. 123, n. 2, p. 121-126. Jun 1997.

KOLLURU, R., BARTELL, S., PITBLADO, R., STRICOFF, R. Risk assessment and management handbook. New York, NY: McGraw Hill, 1996.
LAUFER, A., TUCKER, R. Is construction planning really doing its job ? A critical examination of focus, role and process. Construction Management and Economics, London, v. 5, n. 5, p. 243-266, 1987.

LAUFER, A., TUCKER, R., SHAPIRA, A., SHENHAR, A. The multiplicity concept in construction project planning. Construction Management and Economics, London, v.12, n. 1, p. 5365, 1994.

LISKA, R.W. et al. Zero accident techniques. Austin: The Construction Industry Institute, 1993.

MACKENZIE, J., GIBB, A., BOUCHLAGHEM, M. Communication: the key to designing safely. In: International Congress on Designing for Safety, 1., 2000, London. Proceedings...Loughborough: Loughborough University, 2000. Disponível em <www.eci-online.org $>$. Acesso em: 20 ago. 2000
SAURIN, T.A., FORMOSO, C.T., GUIMARÃES, L.B. Integrating safety into production planning and control process: an exploratory study. In: Annual Conference of the Internationa Group of Lean Construction, 9., 2001, Singapore. Proceedings..., Singapore: National University of Singapore, 2001. Disponível em <http://cic.vtt.fi/lean/ conferences.htm $>$. Acesso em: 28 nov. 2001.

SURAJI, A., DUFF, R., PECKITT, S. Development of causal model of construction accident causation. Journal of Construction Engineering and Management, New York, NY, v. 127, n. 4 p. 337-344. Jul / Aug, 2001

TAH, J. Towards a qualitative risk assessment framework for construction projects. I $n$ : IPMA Symposium on Project Management, 1., 1997, Helsinki. Proceedings...London: E\&FN SPON, 1997. p. $265-274$

\section{- Agradecimentos}

Os autores agradecem à CAPES (Coordenação de Aperfeiçoamento de Pessoal de Nível Superior) e à FAPERGS (Fundação de Amparo à Pesquisa do Estado do Rio Grande do Sul) pelo financiamento concedido à realização desta pesquisa. 